\title{
Effectiveness of Behavioral Activation in Treating Thai Older Adults with Subthreshold Depression Residing in the Community
}

This article was published in the following Dove Press journal: Clinical Interventions in Aging

\author{
Wanvisa Saisanan $\mathrm{Na}$ \\ Ayudhaya (D) $^{\prime}$ \\ Nuttorn Pityaratstian $\left(\mathbb{D}^{2}\right.$ \\ Wiroj Jiamjarasrangsi $\mathbb{D}^{\prime}$ \\ 'Department of Preventive and Social \\ Medicine, Faculty of Medicine, \\ Chulalongkorn University, Bangkok, \\ Thailand; ${ }^{2}$ Department of Psychiatry, \\ Faculty of Medicine, Chulalongkorn \\ University, Bangkok, Thailand
}

Background: In recent years, behavioral activation (BA) has attracted increased interest as an effective depression treatment. However, empirical evidence supporting its effectiveness in non-Western countries is currently limited.

Objective: To examine the effectiveness of BA in reducing depressive symptoms, stress, and anxiety among Thai older adults with subthreshold depression.

Methods and Subjects: A clustered randomized controlled trial was conducted in two health promoting hospitals (HPHs) in the Samut Songkhram province of Thailand. One hospital was used for the intervention (BA+usual care group) and the other for the control (usual care-only group). Each HPH randomly selected 41 eligible older adults residing in their jurisdictions to take part in the study. Mental health outcomes were assessed using the Thai Geriatric Depression Scale (TGDS) and Depression Anxiety Stress Scales (DASS). The BA effectiveness was evaluated using generalized estimating equations (GEE) at a group level and the reliable change index (RCI) at the individual level.

Results: Over 9 months, the adjusted mean change in depression (TGDS) scores [ -2.47 (95\% CI: $-3.84,-1.00)]$, mental health status (DASS), specifically depression and stress score $[-1.47$ and -1.87 (95\% CI: $-2.43,-0.50$ and $-2.94,-0.79$, respectively)], improved significantly in the $\mathrm{BA}+$ usual care group compared to the usual care-only group, whereas anxiety score improved significantly only at 6 months $[-0.87(95 \% \mathrm{CI}:-1.52,-0.23)]$. Additional RCI analysis showed that BA was directly associated with 14.63 to $24.39 \%$ points increase in the reliable improvement of depressive outcome compared to the usual care-only group.

Conclusion: This study showed that the BA effectively improved depression, stress, and anxiety in older adults with subthreshold depression in a Thai community setting. Future research should evaluate the longer-term effectiveness of BA in diverse population groups.

Keywords: behavioral activation, community, depression, older adults

\section{Introduction}

Depression is prevalent worldwide, with reported 322 million people, or $4.4 \%$ of the global population, suffering from its effects. Its prevalence varies with age; however, it typically peaks in older adulthood (above $7.5 \%$ and 5.5\%, respectively, among females and males aged 55-74 years). ${ }^{1}$ Depression is associated with negative health implications, causing significant emotional suffering in older adults, including diminished function and quality of life, cognitive impairments, increased risk of dementia, and morbidity and mortality. ${ }^{2}$ Therefore, identifying and treating
Correspondence: Wiroj Jiamjarasrangsi Department of Preventive and Social Medicine, Faculty of Medicine,

Chulalongkorn University, Rama IV Road, Pathumwan, Bangkok 10330, Thailand

Tel +6622564000 Ext. 3700

Fax +6622564292

Email wjiamja@gmail.com 
depression from the outset can help reduce these adverse health effects and accompanying medical expenses, decreasing the burden on caregivers. ${ }^{3}$

Early intervention targeting older adults with subthreshold (or mild to moderate) depression is of particular interest since this milder state increases the risk of developing a full clinical disorder (or major depression). Subthreshold depression may be more reversible than the advanced clinical state, enabling neurobiological changes at an earlier and more modifiable stage of development. ${ }^{3}$

Behavioral activation (BA) is a psychosocial intervention based on the behavioral model of depression. According to this model, depression is conceptualized as a complex interplay between negative life events, physical and emotional responses to those life events, and ineffective coping behaviors, resulting in further problems over time. ${ }^{4,5}$ The goal of behavioral activation is to break this negative feedback loop by increasing participation in rewarding activities. ${ }^{6}$ During the increased activity, the client has more opportunities to encounter rewarding experiences, which can decrease depression over time. To increase the exposure to positive behavioral consequences, different techniques are used throughout the treatment, particularly the monitoring and scheduling of activities.

Evidence suggests that BA is comparable to Cognitive Behavior Therapy (CBT) and other psychotherapeutic treatments and antidepressant medications in treating depression effectively. ${ }^{7-10}$ While both CBT and BA are recommended, CBT is costly and requires a well-trained therapist, whereas $\mathrm{BA}$ is more convenient, cost-effective, and can be delivered by a non-specialist with minimal training. ${ }^{11,12}$ In addition, BA is culturally adaptable across various international settings ${ }^{13}$ and is effective across a broad range of populations in various settings and services. ${ }^{14}$ A recent systematic review by Orgeta et al suggested that BA is effective for treating older adults with both major depression and depressive symptoms; however, a small number of relevant studies limit us from making any firm conclusions. ${ }^{15}$ Moreover, all but one study was conducted in the USA context. ${ }^{16}$

This study aimed to evaluate BA's effectiveness in treating subthreshold depression among older adults in a Thai community setting. To achieve both the reliable and generalizable results as well as the quantification of treatment outcomes for each participant, the evaluation was conducted both at the group (by the average-based approach) and individual (by the individual-based approach) levels. ${ }^{17}$ Specifically, we aimed to: (a) examine whether those who participated compared to those who did not participate in a
BA intervention would show reduced levels of depression, anxiety, or stress and (b) determine reliable and clinically significant changes in depression, anxiety, and stress levels among individuals participating in the BA intervention.

\section{Materials and Methods}

\section{Participants}

This 2-clustered randomized control trial (RCT) was performed according to the Declaration of Helsinki and was approved by the Institutional Review Board of the Faculty of Medicine, Chulalongkorn University (IRB No. 680/61). All participants provided written informed consent before their participation.

Participants were recruited from the Muang district of Samut Songkram Province, central Thailand. Out of 11 sub-districts, two were randomly selected to be the experimental and control areas (sub-districts A and B). Potential participants were approached at the health promoting hospitals (HPHs) in the two selected sub-districts. A total of 224 and 286 adults aged 60 years or older were screened from sub-districts A and B, respectively. Participants with subthreshold (mild to moderate) depression were identified via the completion of a Thai Geriatric Depression Scale (TGDS) with the assistance of officers at the local subdistrict health promoting hospitals and local Village Health Volunteers (VHVs). A GDS score between 13 and 24 was used to classify subthreshold depression, resulting in 71 and 84 older adults being identified as having subthreshold depression in districts $\mathrm{A}$ and $\mathrm{B}$, respectively. Participants who had any of the following conditions were further excluded: (1) hearing impairment and/or dementia as assessed by the Mini-Mental State Examination Thai version (MMSE-Thai 2002), ${ }^{18}$ (2) psychiatric or medical comorbidities that were potentially life-threatening or expected to severely limit participation or adherence, and (3) current participation in any type of psychotherapy or taking antidepressants. The sample size was calculated according to the formula proposed by Thabane L. (Formulae for Sample Size Calculations for Comparisons Between Means/Two-sample Parallel) ${ }^{19}$ and based on the previously reported mean GDS scores of 15.83 and 13.97 in the control and experimental groups, respectively (with the effect size of 1.86), ${ }^{16}$ the pooled standard deviation of 7.165 , the $80 \%$ power, and statistically significant level of 0.05 , and the possible drop out of $20 \%$. This resulted in an estimated sample size of 41 in each group (Figure 1). However, four participants in the experimental group 


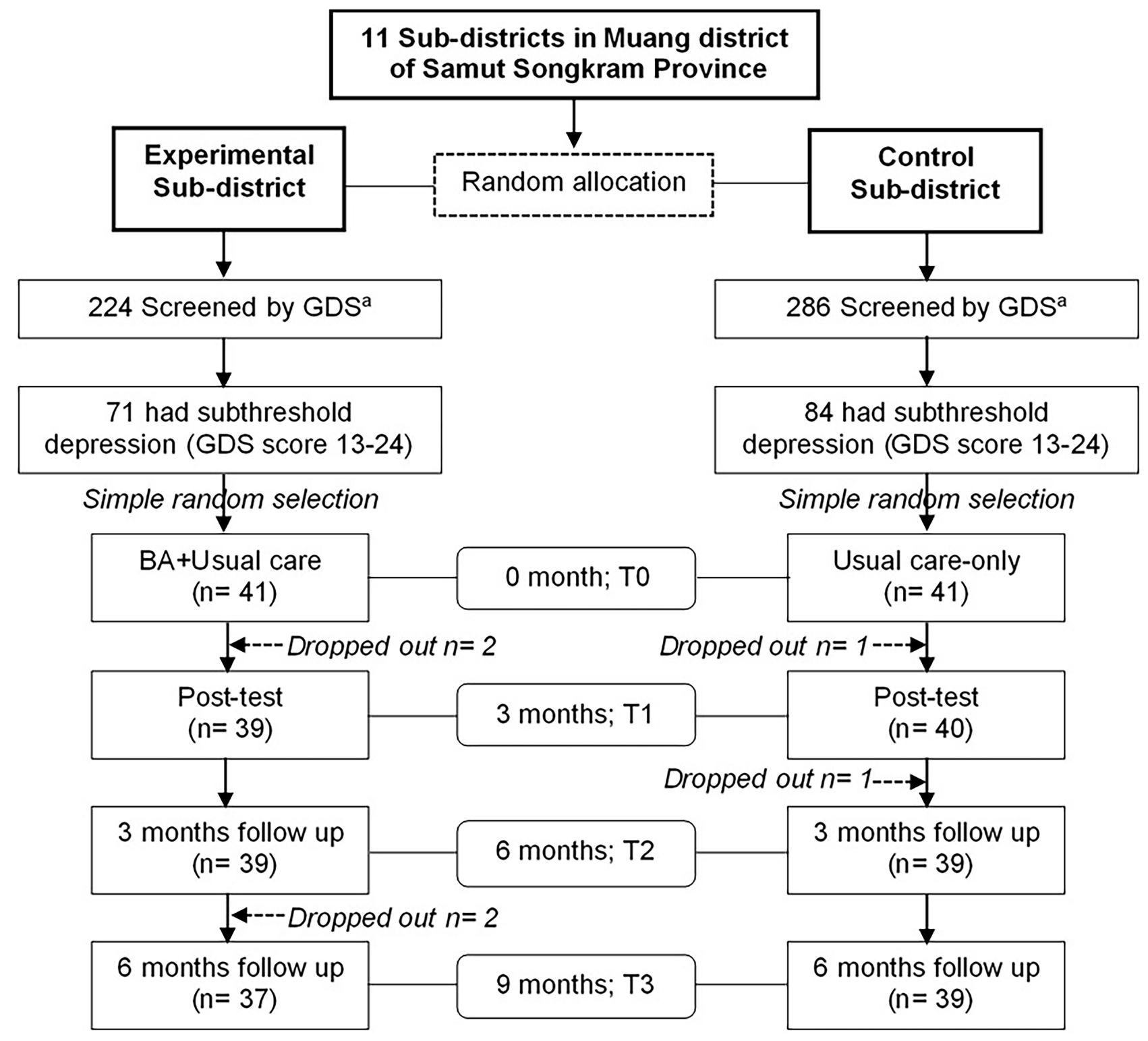

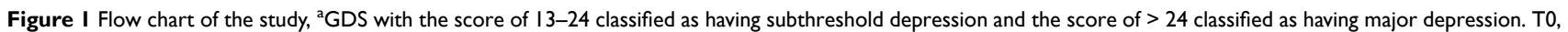
Baseline; TI, at the end of BA intervention of the experimental group or at the end of the 3rd month of the study; T2, 3 months follow-up after the end of the intervention or at the end of the 6th month of the study; T3, 6 months follow-up after the end of the intervention or at the end of the 9th month of the study.

Abbreviations: BA, behavioral activation; GDS, geriatric depression scale.

dropped out (due time constraint), while one participant in the control group dropped out for an unspecified reason, and one died (unrelated to depression) during the followup period. Hence, 37 participants in the experimental and 39 participants in the control group completed the study. The drop-out rates were $9.76 \%$ and $4.88 \%$ in the control and experimental groups, respectively.

\section{Intervention}

The BA intervention aimed to (a) increase engagement in adaptive behaviors and enjoyable activities; (b) decrease engagement in behaviors that maintain depression or increase the risk of depression; and (c) target factors that restrict access to reinforcement or maintain the aversive experience. ${ }^{20}$ The intervention was based on the traditional BA process that emphasizes a contextual understanding of depression and includes three main steps: activity monitoring, activity scheduling, and modification. ${ }^{20,21}$ Before developing the intervention, the principal investigator (WS), who is not a mental health professional, attended a 6-day training course in CBT and BA arranged by a psychiatrist specializing in CBT at the Department of 
Psychiatry, Faculty of Medicine, Chulalongkorn University. The principal investigator subsequently developed a course consisting of 12 x 2-hour weekly sessions conducted over twelve weeks, a course manual, structured agendas for each meeting in the form of checklists, and supporting session materials (Table 1). The content validity of these materials was assessed by three psychiatrists and a geriatric nurse, obtaining an Item-Objective Congruence Index (IOC) of 0.91. The forms used in the intervention were simplified by adding the emotion icons into the daily activity record form to accommodate participants' limited literacy. Participants were also encouraged to seek assistance with form filling from family members and/or village health volunteers (VHVs).

Before the formal BA intervention, a nurse who worked at the local health-promoting hospital and had previous mental health training and nine VHVs were recruited to be a part of the research team. None of them had prior experience in BA. Therefore, they were provided a 1-day training program explaining the purpose of the program, implementation procedures, mental health assessment, and data collection. In all, the BA delivery team was composed of the principal investigator (WS), a psychologist, a local mental health nurse, and nine VHVs. Before commencing the group-based BA intervention, the study participants were divided into 3 groups of 13-14 participants, with 3 VHVs assigned to each of their residential areas to oversee each group during the course sessions. The VHVs were also responsible for following-up and assisting the participants in the residential community.

The baseline BA session (0) was then delivered to the participants on the principles and processes of BA, psychoeducation (the concept of the depressive cycle and prevention of depression), introduction to activity scheduling, and recording the activity schedule form. All participants were assigned to practicing recording on the activity schedule form. Since several participants were illiterate, they were encouraged to seek help from family members and VHVs in this activity. The 12-weekly BA sessions delivered subsequently included (1) activity monitoringexamining the effect of specific activities on mood, (2) activity scheduling-developing a plan to increase pleasant activities, and (3) modification-utilizing problem-solving

Table I Outline of the BA Course

\begin{tabular}{|c|c|c|}
\hline Session & Content & Assignment \\
\hline 0 & $\begin{array}{l}\text { - Overview of the BA course } \\
\text { - Ice-breaking } \\
\text { - Understanding the concept of depression cycle and BA principle } \\
\text { - Introduction to and practice using the daily activity record form }\end{array}$ & - Complete daily activity record form \\
\hline 1 & $\begin{array}{l}\text { - Daily monitoring: Review assignment } \\
\text { - Discussion and brainstorm on pleasant and unpleasant activities } \\
\text { - Introduction and practice recording activity in identification ranking } \\
\text { sheet }\end{array}$ & $\begin{array}{l}\text { - Complete daily activity record form } \\
\text { - Complete Activity Identification ranking sheet }\end{array}$ \\
\hline $2-3$ & $\begin{array}{l}\text { - Daily monitoring: Review assignment } \\
\text { - Recording activity identification ranking sheet }\end{array}$ & $\begin{array}{l}\text { - Complete daily activity record form } \\
\text { - Complete Activity Identification ranking sheet }\end{array}$ \\
\hline $4,6,8,10$ & $\begin{array}{l}\text { - Daily monitoring: Review assignment } \\
\text { - Recording activity identification ranking sheet } \\
\text { - Recording SMART goal and activity modification planning for the } \\
\text { upcoming week }\end{array}$ & $\begin{array}{l}\text { - Complete daily activity record form } \\
\text { - Complete Activity Identification ranking sheet } \\
\text { - Complete SMART goal and planning for the } \\
\text { upcoming week }\end{array}$ \\
\hline $5,7,9,11$ & $\begin{array}{l}\text { - Daily monitoring: Review assignment } \\
\text { - Recording activity identification ranking sheet } \\
\text { - Activity planning for the upcoming week }\end{array}$ & $\begin{array}{l}\text { - Complete daily activity record form } \\
\text { - Complete Activity Identification ranking sheet }\end{array}$ \\
\hline 12 & $\begin{array}{l}\text { - Daily monitoring: Review assignment } \\
\text { - Recording activity identification ranking sheet } \\
\text { - Activity planning for the upcoming week } \\
\text { - Reflection, applying, and evaluation } \\
\text { - Prepare for finality }\end{array}$ & $\begin{array}{l}\text { - Complete daily activity record form } \\
\text { - Complete Activity Identification ranking sheet }\end{array}$ \\
\hline
\end{tabular}

Abbreviation: BA, behavioral activation. 
to alter contextual problems that may be eliciting or maintaining depressed mood (Table 1).

In the usual care-only group, the following services were provided: regular physical examinations, review of current health symptoms upon the individual's health needs, and psychoeducation (similar to the intervention group) delivered by the local mental health nurse weekly for the 12 weeks. The research team standardized this usual care activity to ensure that the same procedure was provided to both the intervention (BA+usual care group) and the usual care-only groups. The principal investigator who oversaw all BA intervention sessions and two cooperative nurses from the two health-promoting hospitals conducted fidelity checks of intervention and care as usual.

\section{Data Collection}

Personal demographic data were collected using an interview questionnaire at baseline (T0) and consisted of two outcome measures: depression as the primary outcome and anxiety and stress as secondary outcomes. These outcomes were also measured at 3 months (T1), 6 months (T2), and 9 months (T3), respectively. Depression was assessed using the 30 self-rated items of the Thai geriatric depression scale (TGDS), ${ }^{22}$ with each response rated on a dichotomous scale 0 and 1. A total score greater than 12 indicates depression, with higher scores suggesting a higher level of depression. Anxiety and stress were assessed using self-reported Depression Anxiety Stress Scales (DASS) questionnaire ${ }^{23}$ containing 21 items (7 items for each category) measured on a 4-point rating scale. The higher the score, the more severe the emotional distress. In our sample, the internal consistencies (Cronbach's Alpha) for the TGDS (0.90) and DASS subscales, specifically Depression (0.84), Anxiety (0.78), and Stress (0.82), demonstrated good reliability. The research staff who were not involved in executing the BA program or usual care activity collected all data.

\section{Statistical Analysis}

STATA version 15 (Stata Corp. 2017. Stata Statistical Software: Release 15. College Station, TX: StataCorp LLC) was used for all statistical analyses. To evaluate the effectiveness of BA intervention at the group level, generalized estimating equations (GEEs) were used to assess withingroup differences across the different time points. The effects of the BA program on TGDS and DASS were then determined using generalized estimating equations (GEEs) based on an intention-to-treat (ITT) analysis. We used the last- observation-carried-forward (LOCF) method to handle missing data during the follow-up. The potential confounding effects of education level and employment status were accounted for in our analysis. A $p$-value of $<0.05$ was considered statistically significant, and between-group Cohen's $\mathrm{d}$ effect sizes and the $95 \%$ confidence intervals were calculated. The effect sizes were interpreted as trivial $(<.2)$, small $(>.2)$, medium $(>.5)$, large $(>.8)$, and very large $(>1.3) .{ }^{24,25}$

To evaluate the effect of BA intervention on individual participants, individual-level change scores of TGDS and DASS were examined in terms of the reliable change and clinically significant change. ${ }^{26}$ First, the reliable change index (RCI) with the corrections for measurement error and practice effects was used to assess individual score differences in the BA+usual care group above what would be expected in the usual care-only comparison group. This was calculated as $\left(\left[\mathrm{X}_{\mathrm{n}}-\mathrm{X}_{0}\right]-\left[\mathrm{M}_{1}-\mathrm{M}_{0}\right]\right) / \mathrm{SD}_{\text {diff, }}$ where $\mathrm{X}_{0}$ and $\mathrm{X}_{\mathrm{n}}$ were the individuals' observed baseline and 3-, 6-, and 9-month follow-up scores, $\mathrm{M}_{0}$ and $\mathrm{M}_{1}$ were the group mean baseline and 3-month follow-up scores, and $\mathrm{SD}_{\text {diff }}$ was the standard deviation of the group baseline-3-month followup difference score ${ }^{27,28}$ The calculation process was divided into two steps. In the first step, the $95 \%$ confidence interval (two-tailed) of the RCI was calculated using the mean scores at baseline $\left(\mathrm{M}_{0}\right)$ and 3-month follow-up $\left(\mathrm{M}_{1}\right)$, standard deviation at baseline $\left(\mathrm{SD}_{0}\right)$, as well as the Cronbach's coefficient alpha $(\alpha)$ of the usual care-only group (Table 2 ). In the second step, RCI was calculated for each participant, and the calculated value was compared with the limiting values calculated above. Those with a value exceeding limiting deterioration or improvement values were classified as having reliable deterioration or improvement, respectively. Second, the clinically significant change of the individual in the BA+usual care group was determined. Since no demographically comparable normative data were available, Criterion A proposed by Jacobson et $\mathrm{al}^{29}$ was used. According to this criterion, a clinically significant change (improvement or deterioration) of the individual was identified when his/her difference between pre- and post-test scores was at least two standard deviations above or below the pre-test mean of the BA+usual care group.

\section{Results}

\section{Participant Characteristics}

The participants' age, gender, marital status, monthly income, living status, personal disease history, baseline MMSE, TGDS, and DASS scores were similar between 
Table 2 Parameters Used to Identify Individual Participants with Reliable Change in Mental Health Outcomes

\begin{tabular}{|l|l|l|l|l|}
\hline \multirow{2}{*}{ Parameters } & \multicolumn{2}{l|}{ Mental Health Outcomes } \\
\cline { 2 - 5 } & TGDS & DASS: Depression & DASS: Anxiety & DASS: Stress \\
\hline$M_{0}$ & 17.07 & 8.44 & 7.24 & 9.20 \\
$M_{1}$ & 16.54 & 8.15 & 7.37 & 8.95 \\
$S_{0}$ & 2.68 & 2.20 & 1.39 & 2.54 \\
$\alpha$ & 0.90 & 0.84 & 0.78 & 0.82 \\
$S D_{\text {diff }}$ & 1.20 & 1.24 & 0.92 & 1.52 \\
$R C l$ & 2.40 & 2.49 & 1.84 & 3.05 \\
Limiting value of deterioration & -2.93 & -2.78 & -1.71 & -3.30 \\
Limiting value of improvement & 1.87 & 2.20 & 1.97 & 2.80 \\
\hline
\end{tabular}

Abbreviations: DASS, Depression Anxiety Stress Scales; $M_{0}$, mean scores at baseline, $M_{\mathrm{l}}$, mean scores at 3-month follow-up; $\mathrm{RCl}$, reliable change index; SD , standard

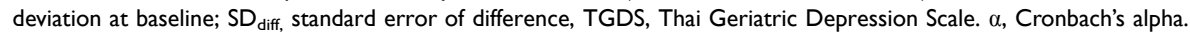

groups (Table 3). However, in the BA+usual care group , a greater number of participants had no education $(p=0.002)$, and unemployment was higher $(p=0.030)$ compared to the usual care-only group (Table 3 ).

\section{Implementation of BA Intervention}

Three courses were offered in 12 weekly BA intervention sessions to three groups of participants in parallel, as planned. Of all 41 participants, two did not attend any session, while the remaining 39 participants attended 6 to 12 sessions, with the mean number of sessions attended being $10.8(\mathrm{SD}=2.2)$. Notably, 32 participants attended all 12 sessions. The number of absentees ranged from 0 to 7 per session, with a median of 1 . Reasons for absence were time conflict with personal business and long holiday leave (mainly during Sessions 5, 6, 11, when numbers of absentees were 7, 5, and 4, respectively). However, all absentees received instruction out-of-classroom from the responsible VHVs and completed all homework assignments.

\section{Group-Level Effect of BA on Mental Health Outcomes}

The group-level evaluation of BA intervention conducted after the 12th week of BA intervention (T1) showed significant reductions in the TGDS score and all component scores of the DASS compared to the usual care-only group (Table 4 and Figure 2). Lower TGDS and DASS depression and stress scores were maintained up to 6 months after completing the BA intervention (T3) (Figure 2A, B, D). However, a significant reduction in DASS anxiety score was maintained only for 3-month post-intervention (T2), returning to baseline levels at 6 months (T3) (Figure 2C). The effect sizes of BA intervention on TGDS score, DASS depression, and stress scores were medium to large $(0.70-1.19)$, while the effect sizes of BA intervention on DASS anxiety score were large at 3 months $(0.80)$ and then dropped to small $(0.48)$ and trivial $(0.05)$ at 6 and 9 months, respectively (Table 4$)$.

\section{Individual-Level Effect of BA on Mental Health Outcomes}

Concerning the effect of BA intervention on the individual participant, the detail of reliable changes in mental health outcomes from baseline overtime is shown in Table 5. For depression outcome measured by the TGDS, the reliable improvement was seen in 6 to 14 out of 41 participants or $14.63 \%$ to $34.15 \%$ in the BA+usual care group, exceeding 6 to 10 out of 41 participants compared to the usual care-only group, accounting for $14.63 \%$ to $24.39 \%$ points. On the contrary, reliable deterioration was not found in both groups.

However, the DASS-depression outcomes were less obvious, in that the magnitudes of excess reliable improvement were $2.44 \%$ to $9.76 \%$, while the magnitudes of excess reliable deterioration ranged between $-2.44 \%, 0 \%$, and $2.44 \%$ points compared to the usual care-only group.

Magnitudes of reliable improvement in DASS-stress outcomes were consistent with those for TGDS depression, with the excess reliable improvement of $0 \%$ to $9.76 \%$ points and the reduced reliable deterioration of $0 \%$ to $2.44 \%$ points in the BA+usual care group compared to the usual care-only group. Different results emerged for DASS-anxiety, for which the magnitudes of excess reliable improvement ranged from $0 \%$ to $17.7 \%$ points, but the magnitudes of reliable deterioration were $-9.75 \%$ to $9.75 \%$ points greater at 6 - and 9-month follow-up compared to those in the usual care-only group (Table 5).

In terms of the clinically significant change, the data were almost consistent with those described above since almost all participants with reliable changes in the psychological 
Table 3 Demographics and Baseline Characteristics of Study Participants $(n=82)$

\begin{tabular}{|c|c|c|c|c|c|}
\hline \multirow{2}{*}{$\begin{array}{l}\text { Characteristics } \\
\text { Age, years: mean }(S D)^{\mathrm{a}}\end{array}$} & \multicolumn{2}{|c|}{ BA+Usual Care Group $(n=4 I)$} & \multicolumn{2}{|c|}{ Usual Care-Only Group $(n=4 I)$} & \multirow{2}{*}{$\begin{array}{l}\mathbf{p} \\
0.336\end{array}$} \\
\hline & 70.54 & $(5.39)$ & 69.20 & $(7.06)$ & \\
\hline \multicolumn{6}{|l|}{ Gender: $\mathrm{n}(\%)^{\mathrm{c}}$} \\
\hline Male & 8 & $(19.5 \mid)$ & 9 & $(21.95)$ & 0.785 \\
\hline Female & 33 & $(80.49)$ & 32 & (78.05) & \\
\hline \multicolumn{6}{|l|}{ Marital status: $n(\%)^{d}$} \\
\hline Single & 6 & $(14.63)$ & 8 & $(19.51)$ & 0.689 \\
\hline Married & 22 & $(53.66)$ & 23 & $(56.10)$ & \\
\hline Widowed/Divorced/Separated & 13 & $(31.71)$ & 10 & (24.39) & \\
\hline \multicolumn{6}{|l|}{ Education: $\mathrm{n}(\%)^{\mathrm{d}}$} \\
\hline None & 2 & $(4.88)$ & 12 & $(29.27)$ & $0.002 *$ \\
\hline Primary school & 38 & $(92.68)$ & 25 & $(60.97)$ & \\
\hline Secondary school and above & 1 & $(2.44)$ & 4 & $(9.76)$ & \\
\hline \multicolumn{6}{|l|}{ Employment: $\mathrm{n}(\%)^{\mathrm{d}}$} \\
\hline Unemployed & 13 & $(31.70)$ & 10 & (24.39) & $0.030 *$ \\
\hline Agriculture & 5 & $(\mid 2.20)$ & 6 & $(14.63)$ & \\
\hline Merchant & 8 & $(19.5 \mathrm{I})$ & 5 & $(12.20)$ & \\
\hline Self employed & 10 & $(24.39)$ & 16 & $(39.02)$ & \\
\hline Housewife/husband & 5 & $(\mid 2.20)$ & 4 & $(9.76)$ & \\
\hline \multicolumn{6}{|l|}{ Living status: $\mathrm{n}(\%)^{\mathrm{d}}$} \\
\hline Living alone & 5 & $(12.20)$ & 3 & $(7.32)$ & 0.503 \\
\hline Live with spouse and children & 29 & $(70.73)$ & 27 & $(65.85)$ & \\
\hline Live with relatives & 7 & $(17.07)$ & 11 & $(26.83)$ & \\
\hline Income: Median (IQR) ${ }^{\mathrm{b}}$ & 800 & $(1300)$ & 700 & $(2400)$ & 0.651 \\
\hline \multicolumn{6}{|l|}{ Personal disease history: $\mathrm{n}(\%)^{\mathrm{c}}$} \\
\hline No & 7 & $(17.07)$ & 6 & $(14.63)$ & 0.545 \\
\hline Yes & 34 & $(82.93)$ & 35 & $(85.37)$ & \\
\hline MMSE score: mean (SD) ${ }^{\mathrm{a}}$ & 19.12 & $(1.72)$ & 18.95 & $(2.37)$ & 0.710 \\
\hline TGDS: mean (SD) ${ }^{\mathrm{a}}$ & 16.49 & $(2.73)$ & 17.07 & $(2.68)$ & 0.330 \\
\hline \multicolumn{6}{|l|}{ DASS: mean $(S D)^{a}$} \\
\hline Depression & 8.20 & $(2.28)$ & 8.44 & $(2.20)$ & 0.623 \\
\hline Anxiety & 7.19 & $(1.55)$ & 7.24 & (1.39) & $0.88 I$ \\
\hline Stress & 8.98 & $(2.16)$ & 9.20 & (2.54) & 0.675 \\
\hline
\end{tabular}

Notes: ${ }^{*} p<0.05$; ${ }^{\mathrm{a}}$ Independent $t$-test; ${ }^{\mathrm{b}}$ Mann-Whitney Test; ${ }^{\mathrm{c}} \mathrm{Chi}$-Square test; ${ }^{\mathrm{d}}$ Fisher Exact Test.

Abbreviations: DASS, Depression Anxiety Stress Scales; MMSE, mini-mental state examination; SD, standard deviation; TGDS, Thai Geriatric Depression Scale.

outcomes also had clinically significant changes. The exceptions emerged only for the DASS-anxiety outcome. Specifically, two participants in the BA+usual care group and three participants in the usual care-only group showed reliable improvement at 9-month follow-up but did not achieve clinically significant improvement (detail not is shown).

\section{Discussion}

Based on the evaluation at both group and individual levels, this study demonstrated that BA effectively reduced depressive symptoms among Thai older adults with subthreshold depression. The group-level analysis showed that the magnitude of the treatment effect was large and sustained for at least 6 months after completing the BA program. The additional individual-level analysis revealed that this had resulted from the BA intervention improving depression outcomes in certain participants while potentially preventing deteriorating outcomes in other participants. Despite a significant reduction in stress levels over a prolonged period, the anxiety reduction was less clear. 
Table 4 Comparison of Adjusted Mean Differences Between BA+Usual Care and Usual Care-Only Participants and the Corresponding Cohen's d Effect Sizes

\begin{tabular}{|c|c|c|c|c|c|c|c|c|c|c|}
\hline \multirow{2}{*}{$\begin{array}{l}\text { Outcomes } \\
\text { TGDS }\end{array}$} & \multicolumn{4}{|c|}{ Mean (SD) } & \multicolumn{4}{|c|}{ Mean Difference $(95 \% \mathrm{Cl})$} & \multirow{2}{*}{\multicolumn{2}{|c|}{$\begin{array}{l}\text { Cohen's d Effect } \\
\text { Size } \\
(95 \% \mathrm{Cl})^{\mathrm{b}}\end{array}$}} \\
\hline & \multicolumn{2}{|c|}{$\begin{array}{l}\text { BA+Usual Care } \\
\text { Group }\end{array}$} & \multicolumn{2}{|c|}{$\begin{array}{l}\text { Usual } \\
\text { Group }\end{array}$} & \multicolumn{2}{|c|}{ Unadjusted } & \multicolumn{2}{|c|}{ Adjusted $^{a}$} & & \\
\hline $\begin{array}{l}\text { Baseline } \\
3 \text { months } \\
6 \text { months } \\
9 \text { months }\end{array}$ & $\begin{array}{l}16.49 \\
12.90 \\
13.37 \\
13.66\end{array}$ & $\begin{array}{l}(2.73) \\
(3.30) \\
(3.77) \\
(3.71)\end{array}$ & $\begin{array}{l}17.07 \\
16.54 \\
16.63 \\
16.02\end{array}$ & $\begin{array}{l}(2.68) \\
(3.16) \\
(2.64) \\
(2.62)\end{array}$ & $\begin{array}{l}-0.69 \\
-3.89 \\
-3.52 \\
-2.67\end{array}$ & $\begin{array}{l}(-2.06,0.68) \\
(-5.28,-2.51) \\
(-4.91,-2.13) \\
(-4.07,-1.27) *\end{array}$ & $\begin{array}{l}-0.64 \\
-3.69 \\
-3.32 \\
-2.42\end{array}$ & $\begin{array}{l}(-2.06,0.78) \\
(-5.11,-2.27) * * \\
(-4.70,-1.90) * * \\
(-3.84,-1.00) *\end{array}$ & $\begin{array}{l}1.12 \\
1.00 \\
0.74\end{array}$ & $\begin{array}{l}(0.65,1.59) \\
(0.54,1.46) \\
(0.29,1.18)\end{array}$ \\
\hline $\begin{array}{l}\text { DASS; Depression } \\
\text { Baseline } \\
3 \text { months } \\
6 \text { months } \\
9 \text { months }\end{array}$ & $\begin{array}{l}8.20 \\
6.10 \\
6.22 \\
6.83\end{array}$ & $\begin{array}{l}(2.28) \\
(1.43) \\
(2.22) \\
(2.16)\end{array}$ & $\begin{array}{l}8.44 \\
8.15 \\
7.98 \\
8.24\end{array}$ & $\begin{array}{l}(2.20) \\
(1.97) \\
(2.51) \\
(1.92)\end{array}$ & $\begin{array}{l}-0.32 \\
-2.15 \\
-1.86 \\
-1.57\end{array}$ & $\begin{array}{l}(-1.28,0.64) \\
(-3.12,-1.18) \text { ** } \\
(-2.84,-0.89) \text { ** } \\
(-2.55,-0.58) *\end{array}$ & $\begin{array}{l}-0.30 \\
-2.10 \\
-1.81 \\
-1.47\end{array}$ & $\begin{array}{l}(-1.26,0.67) \\
(-3.07,-1.14) * * \\
(-2.78,-0.84) * * \\
(-2.43,-0.50) *\end{array}$ & $\begin{array}{l}1.19 \\
0.74 \\
0.69\end{array}$ & $\begin{array}{l}(0.72,1.66) \\
(0.29,1.19) \\
(0.24,1.14)\end{array}$ \\
\hline $\begin{array}{l}\text { DASS; Anxiety } \\
\text { Baseline } \\
3 \text { months } \\
6 \text { months } \\
9 \text { months }\end{array}$ & $\begin{array}{l}7.19 \\
6.27 \\
6.39 \\
6.93\end{array}$ & $\begin{array}{l}(1.55) \\
(1.48) \\
(1.72) \\
(1.59)\end{array}$ & $\begin{array}{l}7.24 \\
7.37 \\
7.15 \\
7.00\end{array}$ & $\begin{array}{l}(1.39) \\
(1.26) \\
(1.48) \\
(1.05)\end{array}$ & $\begin{array}{l}-0.17 \\
-1.35 \\
-1.03 \\
-0.36\end{array}$ & $\begin{array}{l}(-0.81,0.46) \\
(-1.99,-0.71) * * \\
(-1.67,-0.39) * \\
(-1.01,0.29)\end{array}$ & $\begin{array}{l}-0.17 \\
-1.21 \\
-0.87 \\
-0.19\end{array}$ & $\begin{array}{l}(-0.81,0.48) \\
(-1.86,-0.57) * * \\
(-1.52,-0.23) * \\
(-0.84,0.46)\end{array}$ & $\begin{array}{l}0.80 \\
0.48 \\
0.05\end{array}$ & $\begin{array}{l}(0.34,1.25) \\
(0.03,0.91) \\
(-0.38,0.49)\end{array}$ \\
\hline $\begin{array}{l}\text { DASS; Stress } \\
\text { Baseline } \\
3 \text { months } \\
6 \text { months } \\
9 \text { months }\end{array}$ & $\begin{array}{l}8.98 \\
6.68 \\
7.10 \\
7.24\end{array}$ & $\begin{array}{l}(2.16) \\
(2.46) \\
(2.69) \\
(2.02)\end{array}$ & $\begin{array}{l}9.20 \\
8.95 \\
8.98 \\
9.14\end{array}$ & $\begin{array}{l}(2.54) \\
(2.30) \\
(2.70) \\
(2.21)\end{array}$ & $\begin{array}{l}-0.24 \\
-2.23 \\
-1.92 \\
-1.95\end{array}$ & 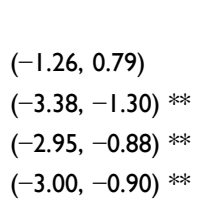 & $\begin{array}{l}-0.18 \\
-2.23 \\
-1.84 \\
-1.87\end{array}$ & $\begin{array}{l}(-1.26,0.89) \\
(-3.30,-1.16) * * \\
(-2.91,-0.77) * \\
(-2.94,-0.79) *\end{array}$ & $\begin{array}{l}0.95 \\
0.70 \\
0.90\end{array}$ & $\begin{array}{l}(0.49,1.41) \\
(0.25,1.14) \\
(0.44,1.35)\end{array}$ \\
\hline
\end{tabular}

Notes: ${ }^{*} p<0.05 ;{ }^{* *} p<0.001$; ${ }^{a} G E E$ was used to analyze the mean difference adjusted for education and employment of each outcome; ${ }^{\mathrm{b}}$ Cohen's $\mathrm{d}$ effect size at 3,6 , and 9 months compared to baseline and interpreted as follows: trivial $(<.2)$, small $(>.2)$, medium $(>.5)$, large $(>.8)$, and very large $(>1.3)$.

Abbreviations: BA, behavioral activation; DASS, Depression Anxiety Stress Scales; SD, standard deviation; TGDS, Thai Geriatric Depression Scale; $95 \%$ CI, $95 \%$ confidence interval.

Our present findings support past observations (mostly from the US) that BA can significantly reduce depressive symptoms in older adults in the community. ${ }^{15}$ Similarly, our results are consistent with Xie et al's work in a primary care setting, showing that modified BA therapy could significantly improve depressive symptoms among rural leftbehind Chinese elderly with mild to moderate depression. ${ }^{16}$ Therefore, our findings add further support to the limited available evidence supporting the effectiveness of the BA treatment in patient sub-groups residing outside of the US. In agreement with Xie et al's work, we found that the BA treatment significantly affected our outcome measures (Table 4). However, this contrasts with Ortega et al's study that reported small to moderate effect sizes. The difference in effect sizes is consistent with a previous systematic review by Cuijpers et al, which showed that effect sizes tended to be larger in non-Western studies. ${ }^{14}$ In our study, larger effect sizes may reflect true differences, indicating that the therapy was indeed more effective. Alternatively, it may indicate that no care was provided in the care as usual control condition or show the relative difference in the trials' quality. ${ }^{30}$ Nevertheless, our data suggest that although BA was developed in the US, it may also be used in the Thai context. Since effective BA treatment can be delivered by a non-specialist mental health worker with minimal previous work experience, ${ }^{31}$ this has beneficial public health implications for less developed countries where depression is prevalent, but healthcare resources are limited.

Based on behavioral theory, the cycle of depression can be reversed through increased activation via increasing participation in behavior that promotes a favorable environment, which is characterized by various potential sources of positive reinforcement and decreased avoidance that inhibits activation. BA participants are asked to act from the "outside-in" rather than from the "inside-out," according to a defined schedule independent of their 

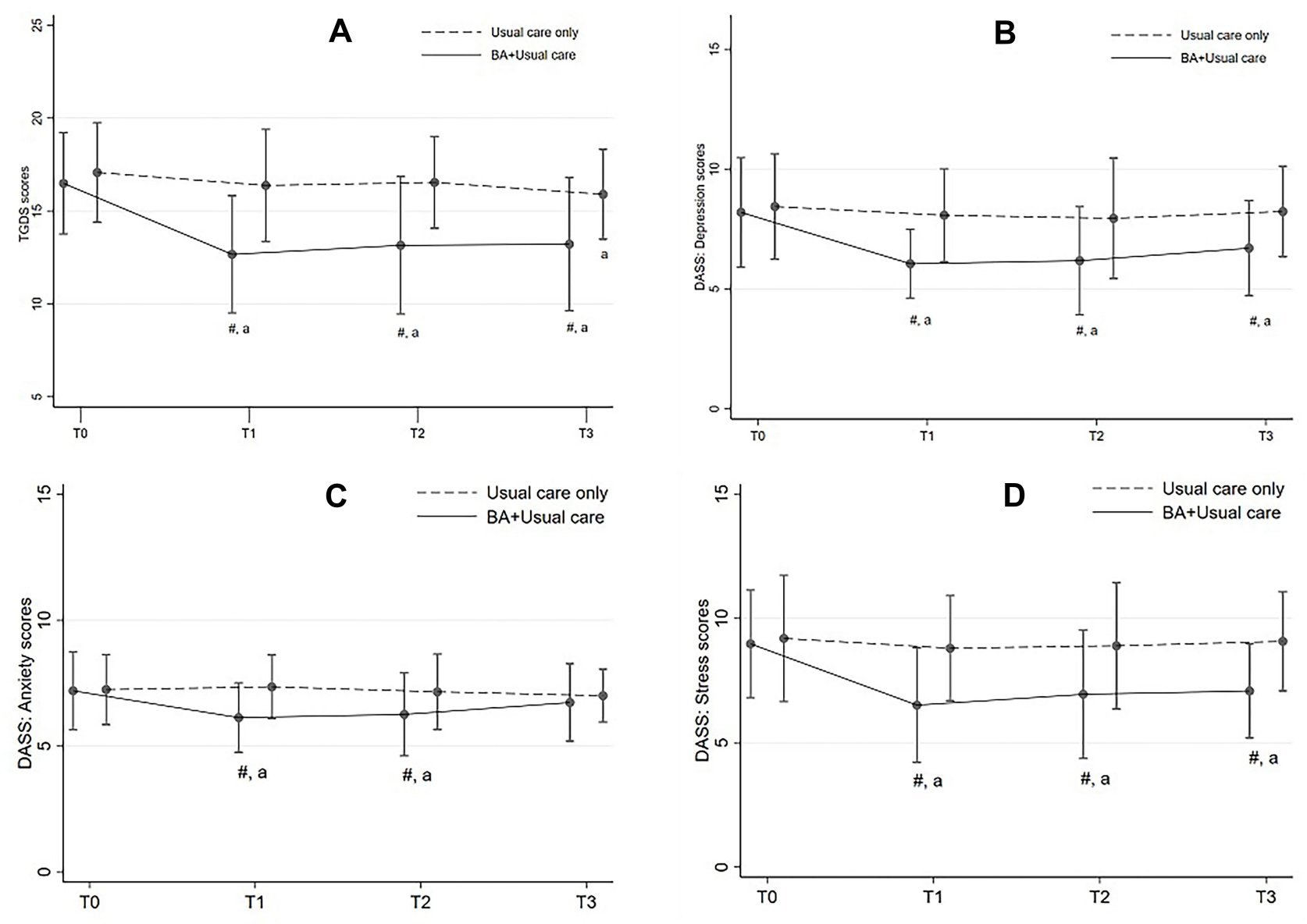

Figure 2 Mean and Standard Deviation Line Charts depicting TGDS and DASS scores at each time point. (A) Mean and standard deviation line chart of TGDS scores. (B) Mean and standard deviation line chart of DASS depression scores. (C) Mean and standard deviation line chart of DASS anxiety scores. (D) Mean and standard deviation line chart of DASS stress scores; \#, significant difference at $p<0.05$ for between-group comparison; a, significant difference between TI to T3 and T0 for within-group comparison. Abbreviations: BA, behavioral activation; DASS, Depression Anxiety Stress Scales; TGDS, Thai Geriatric Depression Scale; T0, 0 months; TI, 3 months; T2, 6 months; T3, 9 months.

mood. ${ }^{6}$ In addition, previous studies have shown a relationship between homework completion and the change in depressive symptomatology. ${ }^{31}$ A previous report of 32 studies suggested that completing general psychotherapy homework has positive results. ${ }^{32}$ In line with our findings, it has also been shown previously that BA treatment delivered by non-specialist mental health workers with minimal previous working ${ }^{33}$ experience results in positive outcomes.

In terms of biological mechanisms, a change in depression is caused by the emotional role of the monoaminergicneurotransmitters that include serotonin, norepinephrine, and dopamine, which are associated with depression and anxiety disorder. ${ }^{34}$ It has been shown that the dopaminergic neurotransmitter in the hypothalamus and pituitary, an important biological precursor for rewarding, concentration, motivation, psychological response, and experience satisfaction may play a role in mood regulation. ${ }^{35}$ Indeed, neurotransmitters, such as dopamine and serotonin, are produced during psychotherapy sessions. For example, the therapist's sudden silence encourages the patient's curiosity and immediately stimulates the secretion of dopamine, the neurotransmitter associated with alertness and awareness. ${ }^{36}$ The first neurobehavioral evidence of BA's effect on subthreshold depression showed increased activation in the dorsal medial prefrontal cortex (dmPFC), leading to improved depression symptoms. ${ }^{37}$ This provides strong evidence linking BA with award behavior, activation, pleasure, and behavioral motivation to reduce depression.

In our study, depressive symptoms, anxiety, and stress measured by the DASS were significantly reduced. Therefore, due to the high comorbidity between depression and anxiety, this observation has clinical significance. ${ }^{38}$ Our findings are consistent with preliminary studies, which have suggested that increased activation in functionally positive areas is associated with decreased anxiety. These studies 
Table 5 Change from Baseline to 3, 6, and 9 Months with Proportions of Cases That Improved and Deteriorated Using the RCl Method

\begin{tabular}{|c|c|c|c|c|c|c|c|c|c|c|c|c|}
\hline \multirow[t]{4}{*}{ Outcomes } & \multicolumn{8}{|c|}{ Reliable Change $^{a}$} & \multirow{2}{*}{\multicolumn{4}{|c|}{ Excess Change $^{b}$}} \\
\hline & \multicolumn{4}{|c|}{ BA+Usual Care Group $(n=4 I)$} & \multicolumn{4}{|c|}{ Usual Care-Only Group $(n=4 I)$} & & & & \\
\hline & \multicolumn{2}{|c|}{ Improve } & \multicolumn{2}{|c|}{ Deteriorate } & \multicolumn{2}{|c|}{ Improve } & \multicolumn{2}{|c|}{ Deteriorate } & \multicolumn{2}{|c|}{ Improve } & \multicolumn{2}{|c|}{ Deteriorate } \\
\hline & $\mathbf{n}$ & $(\%)$ & $\mathbf{n}$ & $(\%)$ & $\mathbf{n}$ & (\%) & $\mathbf{n}$ & $(\%)$ & $\mathbf{n}$ & $(\%)$ & $\mathbf{n}$ & (\%) \\
\hline \multicolumn{13}{|l|}{ TGDS } \\
\hline 3 months & 9 & $(21.95)$ & 0 & $(0)$ & 2 & $(4.88)$ & 0 & $(0)$ & 7 & $(17.07)$ & 0 & (0) \\
\hline 6 months & 6 & $(14.63)$ & 0 & $(0)$ & 0 & $(0)$ & 0 & $(0)$ & 6 & $(14.63)$ & 0 & $(0)$ \\
\hline 9 months & 14 & $(34.15)$ & 0 & $(0)$ & 4 & $(9.76)$ & 0 & $(0)$ & 10 & (24.39) & 0 & (0) \\
\hline \multicolumn{13}{|l|}{ DASS; Depression } \\
\hline 3 months & 3 & $(7.32)$ & 0 & $(0)$ & 0 & $(0)$ & 0 & $(0)$ & 3 & $(7.32)$ & 0 & (0) \\
\hline 6 months & 5 & $(12.2)$ & 0 & $(0)$ & I & $(2.44)$ & 1 & $(2.44)$ & 4 & $(9.76)$ & -1 & $(-2.44)$ \\
\hline 9 months & I & $(2.44)$ & 1 & $(2.44)$ & 0 & $(0)$ & 0 & $(0)$ & I & $(2.44)$ & 1 & $(2.44)$ \\
\hline \multicolumn{13}{|l|}{ DASS; Anxiety } \\
\hline 3 months & 10 & (24.39) & 2 & $(4.88)$ & 3 & $(7.32)$ & 6 & $(14.63)$ & 7 & $(17.07)$ & -4 & $(-9.75)$ \\
\hline 6 months & 10 & $(24.39)$ & 7 & $(17.07)$ & 6 & $(14.63)$ & 3 & $(7.32)$ & 4 & $(9.76)$ & 4 & $(9.75)$ \\
\hline 9 months & 3 & $(7.32)$ & 4 & $(9.76)$ & 3 & $(7.32)$ & 2 & $(4.88)$ & 0 & $(0)$ & 2 & $(4.88)$ \\
\hline \multicolumn{13}{|l|}{ DASS; Stress } \\
\hline 3 months & 1 & $(2.44)$ & 0 & $(0)$ & 0 & $(0)$ & 0 & $(0)$ & I & $(2.44)$ & 0 & $(0)$ \\
\hline 6 months & 5 & $(\mid 2.20)$ & 1 & $(2.44)$ & 1 & $(2.44)$ & 0 & $(0)$ & 4 & $(9.76)$ & I & $(2.44)$ \\
\hline 9 months & 0 & $(0)$ & 0 & $(0)$ & 0 & $(0)$ & 0 & $(0)$ & 0 & $(0)$ & 0 & (0) \\
\hline
\end{tabular}

Notes: ${ }^{a}$ Defined by comparing the reliable change index $(\mathrm{RCl})$ of individual participants with the limiting values of deterioration or improvement; ${ }^{\mathrm{b}} \mathrm{Number}$ (percent) of participants with reliable improvement (or deterioration) in the BA+usual care group - Number (percent) of participants with reliable improvement (or deterioration) in the usual care-only group.

Abbreviations: BA, behavioral activation; DASS, Depression Anxiety Stress Scales; RCl, reliable change index; SD, standard deviation; TGDS, Thai Geriatric Depression Scale.

have demonstrated that participating in 12 weekly 60 -minute BA sessions is potentially effective as a stand-alone treatment for older adults' anxiety. ${ }^{39,40}$ Similar results have been shown in adult women after participating in a nine-week BA intervention. ${ }^{38}$ It is known that stress induces anxiety-like behavior in both humans and animals. ${ }^{41}$ Ern et al showed that positive reinforcement could reduce stress and anxiety, increase confidence, and significantly improve mood. ${ }^{42}$

The overlap between depression and anxiety symptoms ${ }^{43}$ or the fact that anxiety symptoms are secondary to depression $^{44}$ may explain BA's effect on anxiety. These two conditions have multiple symptoms. Some are common for both depression and anxiety, while others are specific to each condition. This suggests that BA may be an appropriate treatment when anxiety symptoms are secondary to depression, as it relieves anxiety symptoms, albeit not to a large degree. The observation of a more rapid decline in anxiety compared with other outcome measures after BA treatment implies that an auxiliary measure, which specifically targets anxiety, is still needed. ${ }^{38}$
Previous meta-analyses have reported that psychotherapies, including BA, are effective and applicable for treating adult depression in various populations and settings, although they may be more or less effective in certain population sub-group(s). ${ }^{13-15}$ Our individual-level analysis revealed that the effectiveness of BA might be selective rather than universal. Focusing on the depression outcome assessed by TGDS and inferring from our calculated excess reliable change shown in Table 5, the BA intervention had a significant positive direct effect on depressive outcomes in $14 \%$ to $24 \%$ of the participants, while the remaining majority of participants did not benefit materially from the intervention. However, limited numbers of individuals with reliable and clinically significant change prevented us from identifying any demographic, clinical, and behavioral factors that may influence the effects of the BA intervention. Further individual-level evaluation studies with larger sample sizes are therefore needed to address this clinically important issue. 


\section{Study Strengths and Limitations}

This study's strengths included its utilization of both the group- and individual-level analytical approaches to evaluating the BA intervention, thus providing additional details on the nature of the intervention effectiveness. It had a high retention rate $(92.7 \%)$, resulting in an adequate statistical power to serve the study objectives. Furthermore, the BA treatment was delivered by a non-specialist (not a mental health professional), ensuring the potential for wider public health applications alongside limited resources. However, the study had several limitations. First, since there was more frequent social contact in the intervention group compared to the control, bias related to the Hawthorne effect cannot be excluded. Second, participant recruitment was confined to a limited area; therefore, future studies may select a more diverse study population to increase the findings' generalizability. Finally, as the study period was only 9 months, whether the BA effect is maintained over the long-term remains to be determined.

\section{Conclusion}

The present study, conducted in a Thai community setting, provides evidence that BA effectively reduces depressive symptoms, stress, and anxiety among older adults with subthreshold depression. Since many clients with subthreshold depression progress to a more severe stage, our findings demonstrate the potential of BA to prevent or reduce the incidence of this major depressive disorder. However, the BA intervention is likely to have individual rather than universal effects. Further studies should be conducted with larger sample sizes to identify factors that explain who is more or less likely to benefit from the BA intervention.

\section{Clinical Implications}

The evaluation at both group and individual levels revealed that $\mathrm{BA}$ is effective in preventing depression among high-risk older adults in non-Western countries.

As BA can be implemented by non-specialized personnel with limited training and prior experience, it is, therefore, a cost-effective measure that has potential for wide application in the primary care and community settings, among others, with limited resource and specialized personnel.

Some adaptation is however required, including the simplification of forms used in the BA implementation to accommodate older adults with limited literacy in developing countries.
Further studies should explore individual-level analysis to subtly identify population subgroup(s) that may or may not benefit from the BA intervention.

\section{Acknowledgments}

The authors would like to thank the officers at the Health Promotion Hospital, Village Health Volunteers (VHVs), and the elderly who participated in this study in Samut Songkhram Province.

\section{Funding}

This research was supported by the 90th Anniversary of Chulalongkorn University, Rachadapisek Sompote Fund, grant number GCUGR1125623018D.

\section{Disclosure}

The authors have no conflicts of interest to declare.

\section{References}

1. World Health Organization. Depression and Other Common Mental Disorders: Global Health Estimates. Geneva: World Health Organization; 2017.

2. Casey DA. Depression in the elderly: A review and update. Asia-Pacific Psychiatry. 2012;4(3):160-167. doi:10.1111/j.1758-5872.2012.00191.x

3. Reynolds CF 3rd, Cuijpers P, Patel V, et al. Early intervention to reduce the global health and economic burden of major depression in older adults. Annu Rev Public Health. 2012;33:123-135. doi:10.1146/ annurev-publhealth-031811-124544

4. Ferster CB. A functional analysis of depression. Am Psychol. 1973;28 (10):857-870. doi:10.1037/h0035605

5. Lewinsohn P. A Behavioral Approach to Depression in RJ Friedman and MM Katz, the Psychology of Depression: Contemporary Theory and Research. Winston; 1974.

6. Martell CR, Dimidjian S, Herman-Dunn R. Behavioral Activation for Depression a Clinician's Guide. A clinician's guide.: Guilford Press; 2013.

7. Cuijpers P, van Straten A, Warmerdam L. Behavioral activation treatments of depression: a meta-analysis. Clin Psychol Rev. 2007;27(3):318-326. doi:10.1016/j.cpr.2006.11.001

8. Ekers D, Webster L, Van Straten A, Cuijpers P, Richards D, Gilbody $\mathrm{S}$. Behavioural activation for depression; an update of meta-analysis of effectiveness and sub group analysis. PLoS One. 2014;9(6): e100100. doi:10.1371/journal.pone. 0100100

9. Luaces LL, Dobson KS. Is Behavioral Activation (BA) More Effective than Cognitive Therapy (CT) in severe depression? A reanalysis of a landmark trial. Int $J$ Cogn Ther. 2019;12:73-82. doi:10.1007/s41811-019-00044-8

10. Mazzucchelli T, Kane R, Rees C. Behavioral activation treatments for depression in adults: a meta-analysis and review. Clin Psychol. 2009;16(4):383-411. doi:10.1111/j.1468-2850.2009.01178.x

11. Ekers D, Richards D, McMillan D, Bland JM, Gilbody S. Behavioural activation delivered by the non-specialist: Phase II randomised controlled trial. British J Psychiatry. 2011;198(1):66-72. doi:10.1192/bjp.bp.110.079111

12. Richards DA, Ekers D, McMillan D, et al. Cost and outcome of behavioural activation versus cognitive behavioural therapy for depression (COBRA): a randomised, controlled, non-inferiority trial. Lancet. 2016;388(10047):871-880. doi:10.1016/s0140-6736 (16)31140-0 
13. Lehmann DC, Bördlein C. A systematic review of culturally adapted behavioral activation treatments for depression. Res Soc Work Pract. 2020;1-15. doi:10.1177/1049731520915635

14. Cuijpers P, Karyotaki E, Reijnders M, Huibers MJH. Who benefits from psychotherapies for adult depression? A meta-analytic update of the evidence. Cogn Behav Ther. 2018;47(2):91-106. doi:10.1080/ 16506073.2017.1420098

15. Orgeta V, Brede J, Livingston G. Behavioural activation for depression in older people: systematic review and meta-analysis. $\mathrm{Br} J$ Psychiatry. 2017;211(5):274-279. doi:10.1192/bjp.bp.117.205021

16. Xie J, He G, Ding S, et al. A randomized study on the effect of modified behavioral activation treatment for depressive symptoms in rural left-behind elderly. Psychother Res. 2017:1-11. doi:10.1080/ 10503307.2017.1364444.

17. Estrada E, Ferrer E, Pardo A. Statistics for evaluating pre-post change: relation between change in the distribution center and change in the individual scores. Front Psychol. 2019;9:2696. doi:10.3389/ fpsyg.2018.02696

18. Institute of Geriatric Medicine. Mini-Mental State Examination-Thai Version (MMSE-Thai 2002). Bangkok: Department of Medical, Ministry of Public Health; 1999.

19. Thabane L. Sample Size determination in clinical trials HRM-733 class notes. Center for Evaluation of Medicines Hamilton, USA: St Joseph's Healthcare. 2004.

20. Dimidjian S, Barrera M Jr, Martell C, Munoz RF, Lewinsohn PM. The origins and current status of behavioral activation treatments for depression. Annu Rev Clin Psychol. 2011;7:1-38. doi:10.1146/ annurev-clinpsy-032210-104535

21. Martell CR, Addis ME, Jacobson NS. Depression in Context: Strategies for Guided Action. New York, N.Y: WW Norton \& Co; 2001.

22. Train The Brain Forum Committee. Thai Geriatric Depression ScaleTGDS. Siriraj Med J. 1994;(46):1-9.

23. Oei TPS, Sawang S, Goh YW, Firdaus M. Using the Depression Anxiety Stress Scale 21 (DASS-21) across cultures. Int J Psychol. 2013;48(6):1018-1029. doi:10.1080/00207594.2012.755535

24. Cohen J. Statistical Power Analysis for the Behavioral Sciences. 2nd ed. New York: Routledge; 1988.

25. Cohen J. A power primer. Psychol Bull. 1992;112(1):155-159. doi:10.1037/0033-2909.112.1.155

26. Evans C, Margison F, Barkham M. The contribution of reliable and clinically significant change methods to evidence-based mental health. Evidence Based Mental Health. 1998;1(3):70-72. doi:10.1136/ebmh.1.3.70

27. Tröster AI, Woods SP, Morgan EE. Assessing cognitive change in Parkinson's disease: development of practice effect-corrected reliable change indices. Arch Clin Neuropsychol. 2007;22(6):711-718. doi:10.1016/j.acn.2007.05.004

28. Barker-Collo SL, Purdy SC. Determining the presence of reliable change over time in multiple sclerosis: evidence from the PASAT, Adjusting-PSAT, and Stroop Test. Int J MS Care. 2013;15(4):170178. doi:10.7224/1537-2073.2013-007

29. Jacobson NS, Follette WC, Revenstorf D. Psychotherapy outcome research: methods for reporting variability and evaluating clinical significance. Behav Ther. 1984;15(4):336-352. doi:10.1016/S00057894(84)80002-7

Clinical Interventions in Aging

\section{Publish your work in this journal}

Clinical Interventions in Aging is an international, peer-reviewed journal focusing on evidence-based reports on the value or lack thereof of treatments intended to prevent or delay the onset of maladaptive correlates of aging in human beings. This journal is indexed on PubMed Central, MedLine, CAS, Scopus and the Elsevier
30. Cuijpers P, Karyotaki E, Reijnders M, Purgato M, Barbui C. Psychotherapies for depression in low- and middle-income countries: a meta-analysis. World Psychiatry. 2018;17(1):90-101. doi:10.1002/ wps. 20493

31. Busch AM, Uebelacker LA, Kalibatseva Z, Miller IW. Measuring homework completion in behavioral activation. Behav Modif. 2010;34(4):310-329. doi:10.1177/0145445510373384

32. Kazantzis N, Deane FP, Ronan KR. Assessing compliance with homework assignments: review and recommendations for clinical practice. $J$ Clin Psychol. 2004;60(6):627-641. doi:10.1002/ jclp.10239

33. Pass L, Hodgson E, Whitney H, Reynolds S. Brief behavioral activation treatment for depressed adolescents delivered by nonspecialist clinicians: a case illustration. Cogn Behav Pract. 2018;25(2):208224. doi:10.1016/j.cbpra.2017.05.003

34. Liu Y, Zhao J, Guo W. Emotional roles of mono-aminergic neurotransmitters in major depressive disorder and anxiety disorders. Front Psychol. 2018;9:2201. doi:10.3389/fpsyg.2018.02201

35. Coppen A. The biochemistry of affective disorders. British $J$ Psychiatry. 1967;113(504):1237-1264. doi:10.1192/bjp.113.504.1237

36. Ginger A, Ginger S. A Practical Guide for the Humanistic Psychotherapist. London, United Kingdom: Taylor \& Francis Ltd; 2018.

37. Shiota S, Okamoto Y, Okada G, et al. Effects of behavioural activation on the neural basis of other perspective self-referential processing in subthreshold depression: a functional magnetic resonance imaging study. Psychol Med. 2017;47(5):877-888. doi:10.1017/ s0033291716002956

38. Hopko DR, Robertson SMC, Lejuez CW. Behavioral Activation for Anxiety Disorders. Behav Anal Today. 2006;7(2):212-232. doi: $10.1037 / \mathrm{h} 0100084$

39. Turner JS, Leach DJ. Brief behavioural activation treatment of chronic anxiety in an older adult. Behav Change. 2009;26(3):214 222. doi:10.1375/bech.26.3.214

40. Turner JS, Leach DJ. Experimental evaluation of behavioral activation treatment of anxiety (BATA) in three older adults. IJBCT. 2010;6 (4):373-394. doi:10.1037/h0100917

41. Liezmann C, Klapp B, Peters EM. Stress, atopy and allergy: A reevaluation from a psychoneuroimmunologic perspective. Dermatoendocrinol. 2011;3(1):37-40. doi:10.4161/derm.3.1.14618

42. Ern LY, Ziyamdeen FSM, Zeidi S, Tamilselvan N, Mohan V. The effect of positive and negative reinforcement on stress, anxiety, confidence, mood and short term memory among medical students. $J$ Social Sci Humanities. 2019;5(3):108-116.

43. Zbozinek TD, Rose RD, Wolitzky-Taylor KB, et al. Diagnostic overlap of generalized anxiety disorder and major depressive disorder in a primary care sample. Depress Anxiety. 2012;29(12):1065-1071. doi:10.1002/da.22026

44. Fava M, Rankin MA, Wright EC, et al. Anxiety disorders in major depression. Compr Psychiatry. 2000;41(2):97-102. doi:10.1016/ s0010-440x(00)90140-8 system, which is all easy to use. Visit http://www.dovepress.com/ testimonials.php to read real quotes from published authors.

\section{Dovepress}

